\title{
CARACTERIZAÇÃO QUÍMICA DE ÓLEOS ESSENCIAIS DE PLANTAS MEDICINAIS
}

\author{
Ranieli Paiva Lopes ${ }^{1}$ \\ Luan I. R. Rocha ${ }^{2}$ \\ Luciana A. Parreira ${ }^{3}$ \\ Luciano Menini ${ }^{4}$
}

Resumo: Os óleos essenciais são substâncias naturais de grande importância econômica, sendo utilizados como medicamentos, perfumarias, alimentos e cosméticos. São obtidos por diferentes métodos de extração e encontrados em diferentes partes das plantas. Desta forma o trabalho teve como objetivo a coleta, preparação e a extração do óleo essencial de várias espécies realizada através de hidrodestilação durante 4 horas utilizando o aparelho Clevenger. Foi avaliado o rendimento de extração do óleo essencial e a sua composição química por cromatografia a gás com detectores FID e Espectrometria de Massas. A identificação dos constituintes dos óleos essênciais foi realizada através de comparação com dados da biblioteca do equipamento de Espectrometria de Massas e os cálculos do Índice de Kovats. Os teores em \% (massa/massa) dos óleo essenciais foram: alecrim 1,13\%, levante 0,58\%, manjericão 0,24\%, hortelã 0,25\% e hortelã pimenta 0,75\%. Foram identificados vários compostos majoritários tais como:alfa-pineno, o-cimene, germacreno- $D$, Linalol, Acetato de linalila e cariofileno.

Palavras-chave: Óleos essenciais; Plantas medicinais; Caracterização química.

\footnotetext{
${ }^{1}$ Bacharelado em Ciências Biológicas/ IFES - Campus de Alegre, Brasil. E-mail: raanielipaiva@hotmail.com.

2 IFES - Campus de Alegre, Brasil. E-mail: luanitalo@hotmai.com.

3 IFES - Campus de Alegre, Brasil. E-mail: luaparreira@hotmail.com.

4 IFES - Campus de Alegre, Brasil. E-mail: Imenini@ifes.edu.br.
} 